\title{
Chapter 9 \\ Project Genesis: A Strategic Review of Neighbourhood Policing in Dorset
}

\author{
Johannes Pieter Oosthuizen and Alison Wakefield
}

\section{Introduction}

Neighbourhood Policing Teams (NPTs) were introduced into Dorset in 2006 and neighbourhoods and boundaries were clearly defined through consultation with partners and communities (HMIC 2008). Dorset Police invested heavily in the creation of these NPTs across the county, but as Police Forces across England \& Wales attempted to deliver their response to public austerity measures from 2010 by introducing change programmes, it is not surprising that these programmes planned to achieve most of their savings by reducing the number of police officers, Police Community Support Officers (PCSOs) and police staff. By August 2013, Dorset Police began to consider ways of improving their operational model of Neighbourhood Policing as they were entering a period of unprecedented challenge and this is when the review (Project Genesis) was initiated.

\section{Methodology}

The project adopted a mixed methods research strategy and the qualitative data was obtained from 18 semi-structured interviews with Neighbourhood Police Sergeants, together with three focus groups consisting of 19 police officers and

J. P. Oosthuizen $(\bowtie)$

University of Winchester, Winchester, UK

e-mail: Johannes.Oosthuizen@winchester.ac.uk

A. Wakefield

University of Portsmouth, Portsmouth, UK 
PCSOs. Electronic surveys were also distributed to 296 Neighbourhood Police Officers and staff from junior to senior ranks and produced an overall response rate of $59 \%$. The quantitative data was taken from independent observational studies on 14 different NPTs in seven police stations on 62 different shifts over several months.

\section{Operational Roles \& Qualitative Data: Views from the Frontline}

Dorset Police utilise three main roles in each of their operational NPTs, namely the Sergeant (supervisor and senior officer on each team), Police Constable and PCSO. Whilst there are additional supporting roles, the NPTs are the primary implementers of Neighbourhood Policing (NP) tactics and strategies within urban and rural areas throughout Dorset. When questioned about their operational procedures, over 77\% (n14) of NPT sergeants stated that there was no adherence to organisational policies when dealing with problems in local communities, which allowed them to develop individualistic solutions. NP Constables were following the same approach and of the 94 PCs participating in the e-survey, 80\% (n62) said that they developed their own bespoke and personalised solutions instead. A similar trend appeared with PCSOs, where 75\% (n60) stated they adopted a similar approach in their roles. Whilst the utilisation of officer discretion is crucial within NP strategies, it is equally important to ensure that a corporate structure and framework exists within which that discretion may be utilised, to ensure that a strategic 'footprint' can clearly be seen in the application of policing responses to public concerns. This view is supported by Her Majesty's Inspectorate of Constabulary (HMIC) (College of Policing 2015), who stated that to effectively tackle public concerns and improve the quality of life in communities, police priorities, using their tasking and coordinating (TCG) process and supported by systems that monitor effectiveness and impact, must reflect the communities' concerns.

\section{Structural Weaknesses}

A review of Dorset Police's policies found that there were additional factors contributing toward a lack of organisational structure. The absence of a strategic focus appeared to be having a detrimental effect on the morale of officers in NPTs, particularly amongst front-line supervisors. When asked to describe the demands of public sector austerity and diminishing police budgets, $72 \%$ (n13) of NPT sergeants said the task was" difficult", "challenging", and" tough". One NPT 
supervisor who had 18 years' police experience and 7 years in Neighbourhood Policing, stated that "for the first time in my career, it has become difficult ..." (interviewee 3). Some interviewees went on to provide some examples, such as not having vehicle transport readily available (interviewee 7) and in some areas highlighting the case that only one NPT Constable was available for 12,000 residents (interviewee $9 \& 10$ ). The most frequent issue was that of diminishing NPT resources, where NPT officers were being abstracted on a regular basis into 24/7 patrol duties, to fill the gaps being created by a lack of recruitment. 62\% (n66) of NP Constables stated they were being routinely detached from their NPT duties due to the Total Resource Management (TRM) policy ${ }^{1}$, which was seen to be the greatest form of intrusion into their NPT roles. Over 50\% of NPT sergeants felt that the future of NP in Dorset was directly linked to resources and one stated that "NP won't continue if our officers keep getting pulled back into patrol duties [interviewee 5]". Another supervisor suggested that "further losses of NPT officers will result in NP becoming a patrol function [interviewee 11]" and another warned that "our numbers will reduce and we will probably only be able to deliver lip-service [interviewee 16]".

\section{Observational Studies: Examining the Data}

NPTs should be responsible and accountable for levels of crime and Anti-Social Behaviour (ASB) in their geographic areas. This is not a new concept and many other forces do this already - recognising that all levels of crime take place in or affect people who live in neighbourhoods (Home Office 2004, p. 16). However, observational data from Project Genesis indicated that more than one third (37\%) of NPT workloads were taken up with secondary tasks, such as administration, travel and custody-related issues and of the remaining $63 \%$, only $8 \%$ was attributed to working with their local communities. Nearly $32 \%$ of NPT activity took place within police stations and only $11 \%$ of their tasks were associated with a specific set of criminal activities ${ }^{2}$, of which $14 \%$ were with non-criminal/ASB/traffic work and $75 \%$ was associated with 'other' types of work, such as crime prevention patrol, reassurance, community meetings or activities specific to drugs, prostitution, etc. Unsurprisingly, PCSOs spent more time dealing with the public $(67 \%)$ than PCs $(58 \%)$.

Observational data showed that activities varied at each of the seven stations and an urban/rural split was apparent. Nearly $75 \%$ of activity was public facing

\footnotetext{
${ }^{1}$ Policy introduced by Dorset Police to move operational resources across the county, according to demand and need, when required. This frequently involved NPT officers being moved to patrol duties away from their geographical responsibilities.

${ }^{2}$ Violence, criminal damage, burglary and hate crime.
} 
at rural stations, compared to $60 \%$ at urban and patrol activity was higher at rural stations $(31 \%)$ than urban $(20 \%)$. The biggest contrasts were observed in administrative tasks (3\% for rural \& $20 \%$ for urban - an observation in line with Dorset crime levels, which were consistently higher in urban areas): engaging local communities with collaborative problem-solving strategies was as low as $2 \%$ in some urban areas and $16 \%$ in rural stations (this highlighted significant weaknesses for NPTs in consulting and engaging the public, as well as attempting to involve local communities in resolving their own problems, particularly in urban areas).

\section{Findings}

Project Genesis produced a total of 44 recommendations and findings were divided into several key areas, such as detailing a precise understanding of the day-to-day operation of NP officers (measuring their activities around the detection, prevention and reduction of crime), how often supervisors, police officers and PCSOs were visible to the public, what strategies were being employed to engage local communities and what additional levels of training and knowledge were required to enhance their operational roles. The qualitative data highlighted how important it was that a coherent strategic concept of NP was understood corporately by managers and staff across all departments, to enable Neighbourhood police officers and PCSOs to provide a targeted and focused delivery. In addition, role profiles should be reviewed periodically, to ensure they are fit for purpose and avoid what is known as 'mission-creep'. Whilst the qualitative data revealed high levels of commitment in many of the officers, the data showed that NP officers only spend $26 \%$ of their time responding to incidents and $22 \%$ of their shift dealing with crime and ASB. These low levels of crime-based activities make it difficult for police officers to fully utilise their warranted powers and if they are to be more responsible and accountable for dealing with crime in their neighbourhoods, their role needs to be more targeted and specific.

Dorset Police has actively supported Neighbourhood Policing since 2006, but the lack of organisational review, training and modernisation has presented significant challenges for them and in September 2015, their Senior Command Team accepted all the recommendations of Project Genesis, introducing an amended model of Neighbourhood Policing for their 71 NPTs. An external validation of this process was recognised by the HMIC (2016), who stated that "the force has a well-established approach to evidence-based policing... The review [Project Genesis] of its neighbourhood policing function resulted in the adoption of best practice, improved services to the public and an increased understanding of communities". 


\section{References}

College of Policing. (2015). Delivering neighbourhood policing - A practice stocktake. Coventry: College of Policing Limited.

HMIC. (2008, September 1). Her majesty's inspectorate of constabulary. Retrieved October 17, 2017, from HMIC Inspection Report: Dorset Police: Neighbourhood Policing: Developing Citizen Focus Policing: http://www.hmic.gov.uk/media/dorset-phase2-neighbourhood-policing-citizen-focus-20080830.pdf

HMIC. (2016). PEEL: Police effectiveness 2015: An inspection of dorset police. London: HMIC.

Home Office. (2004). Building communities, beating crime: A better police service for the 21 st century. Norwich: The Stationery Office.

Open Access This chapter is licensed under the terms of the Creative Commons Attribution 4.0 International License (http://creativecommons.org/licenses/by/4.0/), which permits use, sharing, adaptation, distribution and reproduction in any medium or format, as long as you give appropriate credit to the original author(s) and the source, provide a link to the Creative Commons license and indicate if changes were made.

The images or other third party material in this chapter are included in the chapter's Creative Commons license, unless indicated otherwise in a credit line to the material. If material is not included in the chapter's Creative Commons license and your intended use is not permitted by statutory regulation or exceeds the permitted use, you will need to obtain permission directly from the copyright holder. 